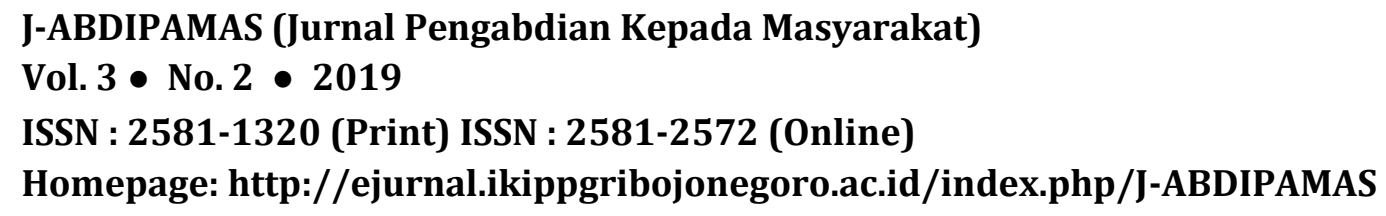

\title{
PENINGKATAN KOMPETENSI GURU MELALUI PELATIHAN PhET SIMULATION BAGI GURU MGMP FISIKA KABUPATEN SERANG
}

\author{
Yoga Budi Bhakti1 ${ }^{1}$ Irnin Agustina Dwi Astuti², Dasmo ${ }^{3}$ \\ ${ }^{1}$ Universitas Indraprasta PGRI. Email: bhaktiyoga.budi@gmail.com \\ 2 Universitas Indraprasta PGRI. Email: irnin.agustina@gmail.com \\ 3 Universitas Indraprasta PGRI. Email: amo0903unindra@gmail.com
}

\begin{abstract}
This program is aimed to increase teacher competency through PhET simulation training. This activity is expected to be used as reference material for teachers to implement practical simulations that caused by time constraints and incomplete laboratory facilities and laboratory facilities. Community service activities are carried out using training, discussion, and mentoring methods. Based on the results of this program, 76.9\% of the training participants really need knowledge of laboratory management. The trainees looked at the PhET simulation material as very relevant to the field of physics. This is proofed by a response of $76.9 \%$ which states that the PhET simulation material is very relevant to learning physics. The trainees also rated very well (92.3\%) the benefits of the knowledge of the use of this media in the physics learning process. This training can be reference for trainees to carry out practicum activities virtually in their respective schools. The trainees found of that PhET simulation easy to understand. This condition can be seen from the results of a survey which stated that $92.3 \%$ of the training participants answered that it was easy to understand this material.
\end{abstract}

Keywords: Phet Simulation, Physics, Teacher Competency Improvement, Virtual Laboratory.

\begin{abstract}
ABSTRAK
Program ini bertujuan untuk meningkatkan kompetensi guru melalui pelatihan PhET simulation. Kegiatan ini diharapkan dapat dijadikan bahan rujukan bagi guru untuk menerapkan simulasi praktikum yang disebabkan oleh keterbatasan waktu dan belum lengkapnya prasarana dan sarana laboratorium praktikum. Kegiatan pengabdian kepada masyarakat ini dilakukan dengan menggunakan metode pelatihan, diskusi, dan pendampingan. Berdasarkan hasil program ini, 76,9\% peserta pelatihan sangat membutuhkan pengetahuan pengelolaan laboratorium. Peserta pelatihan memandang materi PhET simulation sangat relevan dengan bidang fisika. Hal ini dibuktikan dengan respon sebesar 76,9\% yang menyatakan bahwa materi PhET simulation sangat relevan dengan pembelajaran fisika. Peserta pelatihan juga menilai sangat baik (92,3\%) terhadap manfaat pengetahuan penggunaan media ini pada proses pembelajaran fisika. Pelatihan ini bisa menjadi acuan bagi peserta pelatihan untuk melaksanakan kegiatan praktikum secara virtual di sekolah masing-masing. Peserta pelatihan menilai PhET simulation mudah dipahami. Kondisi ini terlihat dari hasil survei yang menyatakan 92,3\% peserta pelatihan menjawab mudah dalam memahami materi ini.
\end{abstract}

Kata Kunci: Phet Simulasi, Fisika, Peningkatan Kompetensi Guru, Laboratorium Virtual 


\section{PENDAHULUAN}

Kualitas guru akan berbanding lurus dengan kualitas pendidikan. Oleh karena itu, peningkatan kompetensi guru merupakan salah satu upaya yang perlu terus dikembangkan dalam rangka mengkualitaskan guru dan berujung pada kualitas pendidikan. Berdasarkan hasil survei terhadap beberapa sekolah di Kabupaten Serang, Banten ditemukan permasalahan bahwa pengelolaan laboratorium fisika masih belum optimal. Kondisi ini diperkuat oleh hasil survei terhadap guru-guru fisika di MGMP fisika Kabupaten Serang, Banten bahwa guru yang melakukan praktikum pada setiap materi pelajaran hanya separuhnya yakni sebesar 52,4\%. Hal ini menunjukkan bahwa masih banyak guru $(47,6 \%)$ yang belum melakukan praktikum di setiap akhir proses belajar mengajar. Setelah ditelusuri lebih jauh, alasan guru tidak melakukan praktikum karena alasan waktu yang terbatas. Hal ini terkait dengan jumlah jam yang tidak sesuai dengan kebutuhan sehingga tidak memungkinkan untuk melakukan praktikum. Selain itu, aktivitas guru fisika yang banyak mendapatkan tugas tambahan dalam pengelolaan sekolah, baik sebagai kepala/wakil kepala sekolah, bendahara, dan jabatan lainnya juga menjadikan kegiatan praktikum sulit diterapkan dalam pembelajaran.

Sumintono (2010) menegaskan, salah satu kesulitan yang dihadapi guru untuk melakukan praktikum di laboratorium adalah dimulai dari sedikitnya waktu, alat bahan yang kurang, ruangan yang terbatas serta ketiadaan laboran. Kondisi ini pulalah yang dihadapi sebagain besar guru fisika yang tergabung dalam MGMP fisika Kabupaten Serang, Banten. Hasil survei menunjukkan bahwa 47,6\% guru menjawab tidak lengkapnya prasarana dan sarana yang dapat digunakan untuk praktikum di sekolah. Meskipun di beberapa sekolah fasilitas prasarana dan sarana sudah lengkap, akan tetapi belum didukung oleh sumber daya manusia yang mampu mengelola laboratorium secara baik.

Berkaca dari permasalahan yang telah diungkapkan, perkembangan teknologi komputer menghadirkan inovasi-inovasi dalam pembelajaran, khususnya fisika. Teknologi komputer adalah sebuah penemuan yang memungkinkan menghadirkan sebagian atau semua bentuk interaksi sehingga pembelajaran akan lebih optimal. Konsep-konsep fisika tersebut direalisasikan dalam komputer menggunakan piranti lunak yang mudah dipelajari (Gunawan, 2015). Komputer dapat dijadikan sebagai media simulasi praktikum pembelajaran yang efektif dan efisien. Salah satu simulasi virtual yang dapat digunakan adalah simulasi Physics Education Technology (PhET).

PhET adalah simulasi yang dibuat oleh University of Colorado yang berisi simulasi pembelajaran fisika, biologi, dan kimia untuk kepentingan pengajaran di kelas atau belajar individu. Simulasi PhET menekankan hubungan antara fenomena kehidupan nyata dengan ilmu yang mendasari, mendukung pendekatan interaktif dan konstruktivis, memberikan umpan balik, dan menyediakan tempat kerja kreatif (Finkelstein, 2006). Melalui media ini, praktikum dapat disimulasikan secara virtual sehingga lebih menghemat waktu dan tidak menghilangkan tujuan praktikum (Astuti \& Handayani, 2018). Praktikum sebagai jembatan konsep teori dan kejadian yang sebenarnya dapat disimulasikan melalui media interaktif (Bhakti \& Napis, 2018). 
Berdasarkan permasalahan mitra tersebut, maka program pengabdian kepada masyarakat ini dilakukan dengan tujuan untuk meningkatkan kompetensi guru melalui pelatihan PhET simulation. Selain itu, kegiatan ini diharapkan dapat dijadikan bahan rujukan bagi guru untuk menerapkan simulasi praktikum yang disebabkan oleh keterbatasan waktu dan belum lengkapnya prasarana dan sarana laboratorium praktikum.

\section{METODE PELAKSANAAN}

Kegiatan pengabdian kepada masyarakat ini telah dilaksanakan di MGMP Fisika Kabupaten Serang yang berpusat di SMA Negeri 1 Kramatwatu, Kabupaten Serang, Banten. Kegiatan ini dilaksanakan pada bulan Mei sampai dengan Juli 2019. Bahan yang digunakan dalam kegiatan ini adalah laptop, modul PhET simulation, dan LCD proyektor.

Metode yang digunakan dalam kegiatan pengabdian kepada masyarakat ini adalah metode pelatihan, diskusi, dan pendampingan. Pelatihan dilakukan dengan cara memberikan pelatihan seputar konsep, dan penggunaan PhET simulation dalam pembelajaran.

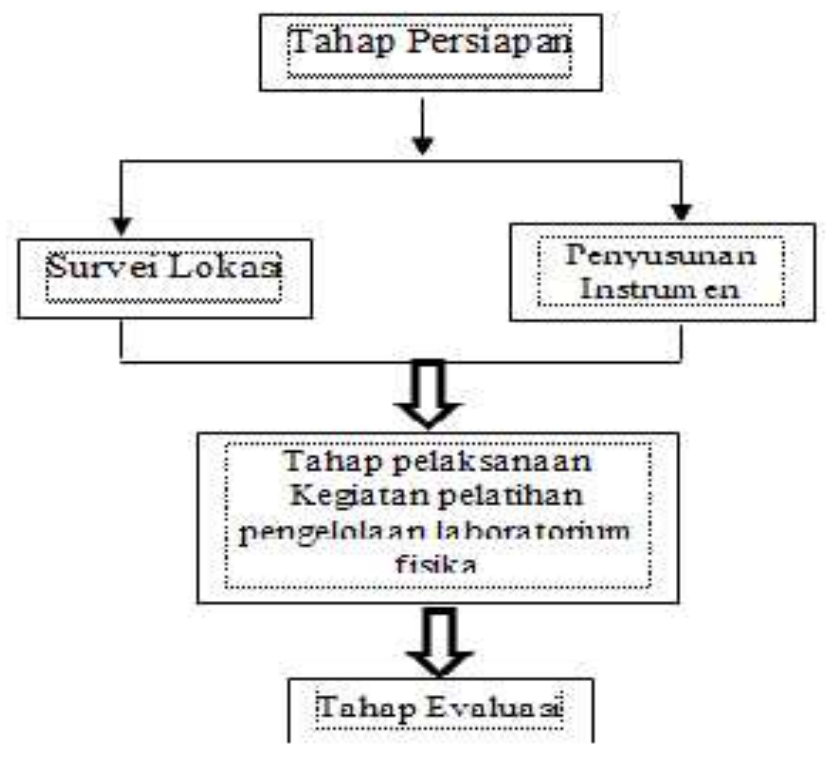

Gambar 1. Diagram Alur Kegiatan Pengabdian Kepada Masyarakat

Pelaksanaan kegiatan ini dilakukan dalam tiga tahapan yaitu tahap persiapan, pelaksanaan, dan evaluasi yang dijabarkan sebagai berikut.

1. Tahap persiapan. Pada tahap persiapan, tim abdimas melakukan survei pendahuluan untuk menganalisis lokasi mitra, kebutuhan pelatihan yang dibutuhkan mitra, dan menyusun rancangan kegiatan yang akan dilakukan, serta menyusun instrumen.

2. Tahap pelaksanaan. Pada tahap ini, tim abdimas, melakukan pelatihan penggunaan media PhET simulation yang ditujukan kepada seluruh guru fisika SMA yang tergabung dalam MGMP Fisika Kabupaten Serang, Banten. Kegiatan ini dilakukan dengan tujuan agar guru dapat meningkatkan kompetensinya melalui pelatihan PhET simulation. Selain itu, kegiatan ini diharapkan dapat dijadikan bahan rujukan 
bagi guru untuk menerapkan simulasi praktikum yang disebabkan oleh keterbatasan waktu dan belum lengkapnya prasarana dan sarana laboratorium praktikum.

3. Tahap evaluasi. Pada tahap ini, tim abdimas melakukan evaluasi terhadap proses kegiatan. Evaluasi dilakukan dimulai dari pra pelaksanaan yang meliputi analisis kebutuhan mitra, kehadiran peserta pelatihan, respon serta saran terhadap kegiatan.

\section{HASIL DAN PEMBAHASAN}

Program pengabdian kepada masyarakat ini telah dilaksanakan di MGMP fisika Kabupaten Serang, Banten. Realisasi kegiatan ini dilakukan dalam tiga tahap, yakni tahap persiapan, pelaksanaan dan evaluasi. Tahap pertama adalah tahap persiapan. Pada tahap ini tim melakukan survei pendahuluan bulan Mei 2019 untuk mengetahui kondisi pada mitra dengan menganalisis kondisi tempat yang akan digunakan, kondisi peserta yang akan diberikan perlakuan (guru fisika yang tergabung dalam MGMP fisika Kabupaten Serang, Banten) dan menyusun rancangan kegiatan yang akan dilakukan. Tahap persiapan selanjutnya, tim menyiapkan bahan presentasi, modul PhET simulation, sarana dan prasarana untuk melengkapi kegiatan pelatihan seperti laptop dan LCD proyektor untuk pemaparan materi.

Tahap selanjutnya adalah tahap pelaksanaan. Pada tahap ini tim melakukan pelatihan mengenai konsep dan penggunaan PhET simulation dalam pembelajaran fisika. Pelatihan dilaksanakan selama 1 hari yakni tanggal 20 Juli 2019. Pelatihan dihadiri 30 orang guru fisika yang tergabung dalam MGMP fisika Kabupaten Serang, Banten. Kegiatan dilakukan dengan memberikan pre-test kepada peserta pelatihan. Pretest yang diberikan bertujuan untuk mengetahui kondisi kemampuan awal peserta pelatihan. Kegiatan dilanjutkan dengan memberikan kuis motivasi agar peserta pelatihan memiliki kemauan untuk berubah ke arah yang lebih baik dan mengikuti pelatihan dengan semangat sampai dengan selesai. Kegiatan dilanjutkan dengan melakukan presentasi materi peran, fungsi dan penggunaan PhET simulation dalam pembelajaran fisika. Selain presentasi, kegiatan diisi dengan diskusi, studi kasus dan praktik penggunaan PhET simulation dalam pembelajaran.

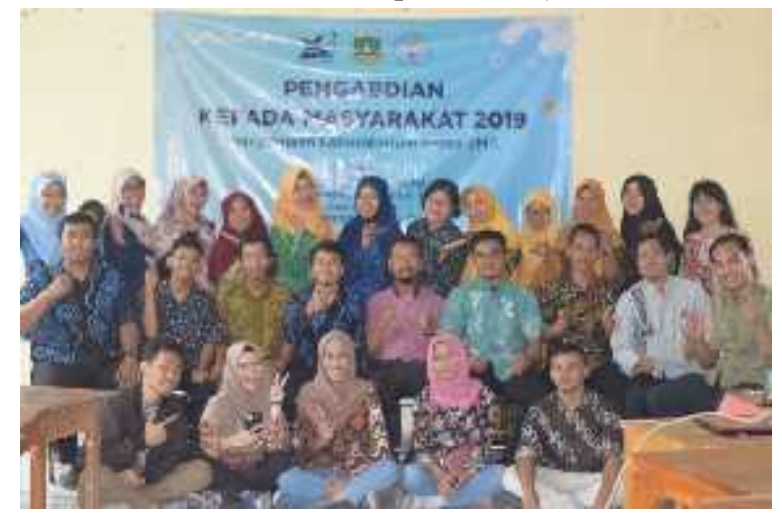

Gambar 1. Tim Abdimas dan Peserta Pelatihan 


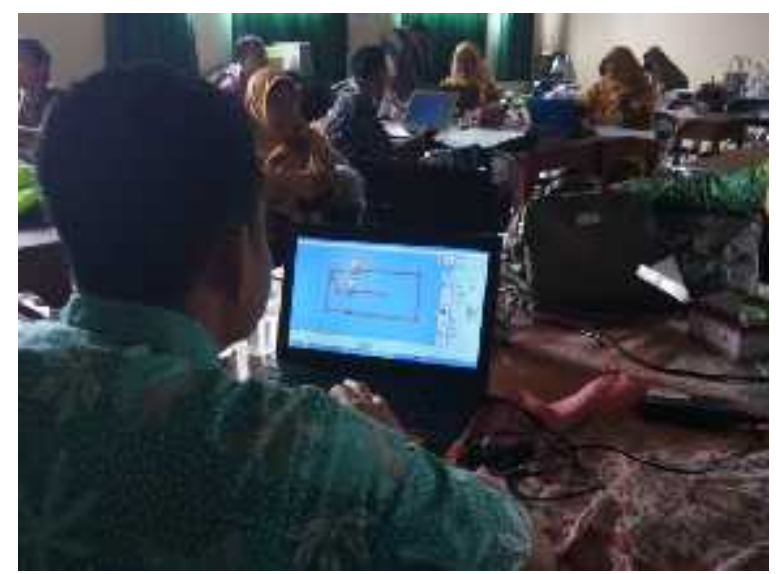

Gambar 2. Aktivitas Pelatihan PhET Simlutaion

Tahap terakhir adalah tahap evaluasi. Pada tahap evaluasi tim juga menganalisis kegiatan selama pelatihan. Pada tahap ini tim datang ke sekolah pada tanggal 27 Juli 2019 untuk memonitoring penggunaan PhET simulation dalam pembelajarn fisika. Hasil monitoring dijadikan sebagai bahan evaluasi untuk kegiatan-kegiatan yang akan dilaksanakan selanjutnya.

Berdasarkan hasil penilaian pelaksanaan pelatihan, 76,9\% peserta pelatihan sangat membutuhkan pengetahuan mengenai topik pengelolaan laboratorium. Akan tetapi, dengan keterbatasan prasarana dan sarana yang ada, guru memerlukan media lain yang lebih simpel, efektif dan efisien yang mampu menggantikan peran laboratorium dalam praktikum. Pada kegiatan ini masih banyak guru yang belum mengenal PHET simulation. PHET simulation merupakan kegiatan praktikum yang dilakukan secara virtual. Melalui media ini, guru tidak perlu menggunakan alat-alat laboratorium untuk praktikum, melainkan praktikum dapat dilakukan secara virtual. Hal ini memberikan pemahaman baru bagi guru dalam melakukan proses pembelajaran.

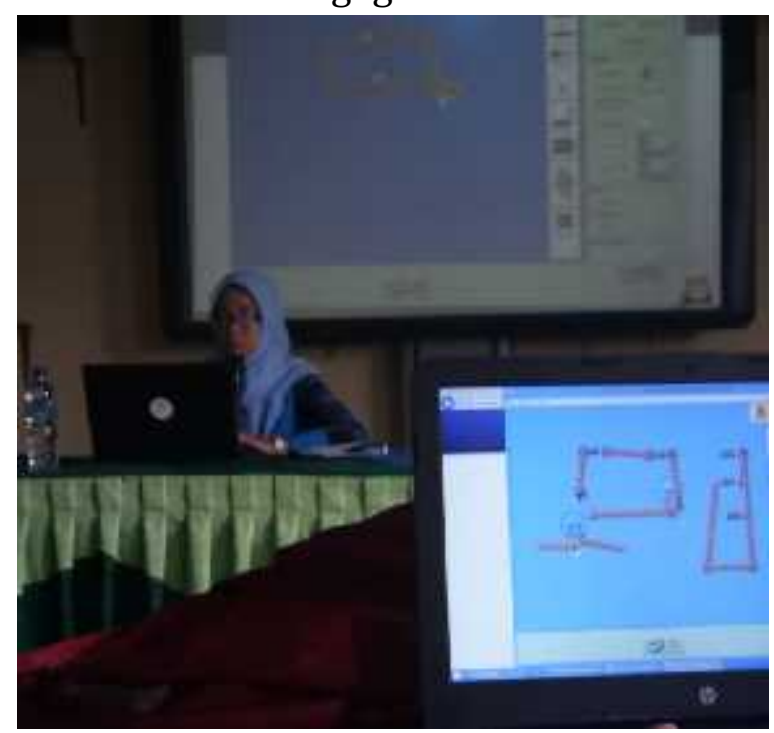

Gambar 3. Pemaparan Materi Pelatihan

PhET simulation dapat dijadikan sebagai solusi alternatif sebagai media virtual pengganti praktikum. Hal ini senada dengan penelitian yang dilakukan oleh Taufiq (2008) yang menyimpulkan bahwa, simulasi PhET memberikan kesan yang positif, menarik, dan menghibur serta membantu penjelasan secara mendalam tentang suatu 
fenomena alam. Oleh karena itu, siswa yang berlatih simulasi PhET merasa senang dan mudah untuk mempelajarinya. Kondisi inilah yang juga terjadi ketika pelatihan ini dilaksanakan, dimana guru sangat antusias dan terlibat aktif dalam diskusi untuk dapat menerapkan media ini dalam proses pembelajaran fisika di kelas.

Peserta pelatihan memandang materi PhET simulation sangat relevan dengan bidang fisika. Hal ini dibuktikan dengan respon sebesar 76,9\% yang menyatakan bahwa materi PhET simulation sangat relevan dengan pembelajaran fisika. Peserta pelatihan juga menilai sangat baik $(92,3 \%)$ terhadap manfaat pengetahuan penggunaan media ini pada proses pembelajaran fisika. Pelatihan ini menjadi acuan bagi peserta pelatihan untuk melaksanakan kegiatan praktikum secara virtual di sekolah masing-masing. Peserta pelatihan menilai topik PhET simulation mudah dipahami. Kondisi ini terlihat dari hasil survei yang menyatakan $92,3 \%$ peserta pelatihan menjawab mudah dalam memahami materi ini.

Berdasarkan hasil tersebut, media virtual PhET simulation dapat dijadikan sebagai solusi alternatif keterbatasan dalam praktikum. Gunawan (2015) menjelaskan bahwa, multimedia terdiri dari berbagai jenis media untuk menyampaikan pesan/informasi kepada pengguna sesuai tujuan dan fungsinya. Terdapat beberapa komponen utama multimedia yang dirangkai dalam format digital yang disusun sedemikian rupa sehingga menarik dan memotivasi pengguna untuk belajar. Komponenkomponen tersebut adalah teks, gambar, audio, video, dan animasi. Satu komponen lagi bisa ditambahkan yaitu interaktif, sehingga multimedia bisa disebut sebagai multimedia interaktif. Zacharia (2003) menegaskan bahwa, penggunaan multimedia interaktif dapat lebih meningkatkan kemampuan inferensi logika dan kemampuan menarik kesimpulan, begitu pun halnya dengan penggunaan laboratorium virtual. PhET simulation merupakan salah satu produk yang bisa digunakan untuk bereksperimen.

PhET juga menyediakan berbagai eksperimen jika di laboratorium alat dan bahan kurang memadai. PhET menekankan hubungan antara fenomena kehidupan nyata dengan ilmu yang mendasari, mendukung pendekatan interaktif dan kontrukvis, memberikan umpan balik, dan menyediakan tempat kerja (Swandi dkk, 2014). Kelebihan dari simulasi PhET yakni dapat melakukan percobaan secara ideal, yang tidak dapat dilakukan dengan menggunakan alat yang sesungguhnya. Dipilihnya simulasi PhET ini karena simulasi ini berbasis program java yang memiliki kelebihan yakni easy java simulation (ejs) yang dirancang khusus untuk memudahkan analisis konsep fisika dalam bentuk simulasi fisika dengan memanfaatkan komputer (Fithriani dkk, 2016). Dengan phET simulation analisis-analisis fisika yang dilakukan diharapkan mampu menjelaskan konsep-konsep abstrak menjadi nyata (Mubarok \& Mulyaningsih, 2014).

\section{SIMPULAN}

Secara keseluruhan kegiatan pengabdian mayarakat yang dilaksanakan di MGMP fisika Kabupaten Serang, Banten berjalan dengan baik. Peserta pelatihan sangat membutuhkan pelatihan dalam rangka mendukung proses pembelajaran yang optimal. Kegiatan ini mendapatkan respon yang positif berdasarkan kebutuhan pengetahuan mengenai pengelolaan laboratorium, relevansi materi, dan manfaat pelatihan. Kegiatan 
ini telah mampu memberikan manfaat pengetahuan pada proses pembelajaran fisika. Pelatihan ini menjadi acuan bagi peserta pelatihan untuk melaksanakan kegiatan praktikum secara virtual di sekolah masing-masing melalui PhET simulation.

\section{UCAPAN TERIMA KASIH}

Penulis mengucapkan terima kasih kepada: 1) Direktorat Riset dan Pengabdian Masyarakat Direktorat Jenderal Riset dan Pengembangan Kementerian Riset, Teknologi, dan Pendidikan Tinggi yang telah memfasilitasi dan memberikan hibah untuk kegiatan abdimas ini, 2) Lembaga Penelitian dan Pengabdian Kepada Masyarakat Universitas Indraprasta PGRI yang telah membantu dan memfasilitasi pelaksanaan kegiatan abdimas dan 3) MGMP Fisika Kabupaten Serang, Banten yang bersedia menjadi mitra dalam pelaksanaan kegiatan abdimas ini.

\section{DAFTAR RUJUKAN}

Astuti, I. A. D., \& Handayani, S. (2018). Penggunaan Virtual Laboratory berbasis PhET Simulation Untuk Menentukan Konstanta Wien. Jurnal Penelitian Pembelajaran Fisika, 9(2), 1-6.

Bhakti, Y. B., \& Napis, N. (2018). The Development Of Guided Inqury Work Sheet For Student With Physics Interactive Simulation. Jurnal Pendidikan Fisika, 7(2), 124-130.

Finkelstein, et.al. (2005). "When Learning About the Real World is Better Done Virtually: A Studi of Substitutung Computer Simulations for Laboratory Equipment". Physics Education Research. APS (1) 1-8.

Fithriani, S. L., Halim, A., \& Khaldun, I. (2016). Penggunaan media simulasi phet dengan pendekatan inkuiri terbimbing untuk meningkatkan keterampilan berpikir kritis siswa pada pokok bahasan kalor di SMA Negeri 12 Banda Aceh. Jurnal Pendidikan Sains Indonesia, 4(2), 45-52.

Gunawan. (2015). Model Pembelajaran Berbasis ICT. Mataram: FKIP Unram Press.

Mubarrok M F \& Mulyaningsih S. (2014). Penerapan Pembelajaran Fisika pada Materi Cahaya dengan Media PhET Simulations Untuk Meningkatkan Pemahaman Konsep Siswa di SMP. Jurnal Iovasi Pendidikan Fisika, 3(1), 76-80.

Sumintono, M. B., Ibrahim, M.A., \& Phang, F. A. (2010). Pengajaran Sains dengan Praktikum Laboratorium: Perspektif dari Guru-guru Sains SMPN di Kota Cimahi. Jurnal Pengajaran MIPA, 15 (2), 120-127.

Swandi, A., Hidayah, S. N., \& Irsan, L. J. (2014). Pengembangan Media Pembelajaran Laboratorium Virtual untuk Mengatasi Miskonsepsi Pada Materi Fisika Inti di SMAN 1 Binamu, Jeneponto. Jurnal Fisika Indonesia, 18(52), 20-24. 
62 J-Abdipamas, Vol. 3, No. 2 Oktober, 2019

Taufiq, M. (2008). Pembuatan Media Pembelajaran Berbasis Compact Disc untuk Menampulkan Simulasi dan Virtual Labs Besaran-besaran Fisika. J. Pijar MIPA, 3 (3), 68-72.

Zacharia, Z. \& Anderson, O.R. (2003). The Effect of an Interactive Computer-Based Simulation Prior to Performing A Laboratory Inquiry-Based Experiment on Students Conceptual Understanding of Physics. American Journal of Physics, 71 (6), 618-629. 